Int. J. Electrochem. Sci., 15 (2020) 10694 - 10706

\title{
Strength Characteristics and Electrochemical Impedance Spectroscopy Characterization of Red Mud-Coal Metakaolin Geopolymers
}

\author{
Jianping Liu ${ }^{1}$, Yisi Lu ${ }^{1}$, Xiaohong Bai ${ }^{1,2, *}$, Pengju Han ${ }^{1}$, Ruizhen Xie ${ }^{3}$, Bin He $e^{1,4}$ \\ ${ }^{1}$ College of Civil Engineering, Taiyuan University of Technology, Taiyuan 030024, China \\ ${ }^{2}$ Key Laboratory of Geotechnical and Underground Engineering of Shanxi Province, Taiyuan 030024, \\ China \\ ${ }^{3}$ Mechanics Institute, Jinzhong University, Taiyuan 030619, China \\ ${ }^{4}$ State Key Laboratory of Geomechanics and Geotechnical Engineering, Institute of Rock and Soil \\ Mechanics, Chinese Academy of Sciences, Wuhan, 430071, China \\ *E-mail: bxhong@tyut.edu.cn
}

doi: $10.20964 / 2020.11 .03$

Received: 16 July 2020 / Accepted: 31 August 2020 / Published: 30 September 2020

In this paper, the compressive strength and electrochemical impedance spectroscopy (EIS) of red mudcoal metakaolin (RM-CMK) geopolymers with different $\mathrm{Na} / \mathrm{Al}$ atomic molar ratios at the age of $28 \mathrm{~d}$ were tested and analyzed. The Na/Al atomic molar ratio had significant influence on the compressive strength and EIS of the RM-CMK geopolymers. With increasing Na/Al, the compressive strength of the RM-CMK geopolymer first increased and then decreased. When Na/Al was 1.0, the compressive strength reached the maximum. The EIS results yielded a Nyquist diagram that presented flat capacitive reactance arcs in the high-frequency region and insignificant diffusion curves in the low-frequency region. The Bode diagram showed that with increasing $\mathrm{Na} / \mathrm{Al}$, the peak values of the impedance modulus and phase angle both first increased and then decreased. When $\mathrm{Na} / \mathrm{Al}$ was 1.0 , the peak values of the impedance modulus and phase angle reached the maximum. Combined with the variation law of EIS, the equivalent circuit of the RM-CMK geopolymer was determined to be $R_{e}\left(C\left(R_{c t} W\right)\right)$. In addition, by means of a scanning electron microscope (SEM), images of the RM-CMK geopolymer microstructure were obtained. The changes in the strength and electrochemical responses of the RM-CMK geopolymer were explained from the microscopic perspective. In this study, EIS was used to test and analyze the electrochemical impedance characteristics of the geopolymer. This proved the feasibility of the application of EIS technology to geopolymer strength analysis. It also provided new ideas and means for the nondestructive testing technology of geopolymers.

Keywords: geopolymer, compressive strength, EIS, microstructure, equivalent circuit 


\section{FULL TEXT}

(C) 2020 The Authors. Published by ESG (www.electrochemsci.org). This article is an open access article distributed under the terms and conditions of the Creative Commons Attribution license (http://creativecommons.org/licenses/by/4.0/). 